\title{
Strategic Business Unit to Spiritual Business Unit: A complete Organizational Transformation
} ANKUR MEHTA

\begin{abstract}
In the fast changing business dynamics and ever growing challenges, organizations are seeking for developmental solutions on both technical and human front. As technical solutions can be a quick fix approach, human challenges takes time to be resolved and transform into a culture statement. The crisis of ethics and moral values while practicing the Corporate Governance ${ }^{1}$ due to the prevailing mindset and the practices has evolved new scams and scandals leading to bankruptcies and recessions. On one hand we talk about Human Rights commission and at the same time layoffs, harassment, back stabbing, whistle blowing and practices like moonlighting are becoming a culture statement. This paper focuses upon creating a proper blend of learning from the East and the ongoing practices from the West to build Spiritual Business Units by applying the Yug Nirman postulates propagated by Yugrishi Pt. Sriram Sharma Acharya. It is an attempt to bridge the gaps in the existing practices and basic principles. Also, it tries to address the need to look back at our native models of development and avoid the alarming situations of the Wall Street or Times Square, which is a consequence of their glamorous looking materialistic yet hollow business models, by revitalizing and rejuvenating the value based Indian approach, which made us prosperous and lead the world economy. As a matter of fact Maddison notes that India was contributing $32.9 \%$ of the Global GDP during the beginning of the Common Era, i.e 2009 years back. An economy that remained as the most prosperous one for many centuries with successful businesses must have had very good management systems. We have to remember here that India was not just the major economic power, but also the premier centre for educational, scientific, intellectual and spiritual activities with pioneering contributions in diverse fields.
\end{abstract}

Key words: Strategic Business Unit, Spiritual Business Unit and Organizational Transformation

Over the past century management practices have continuously been evolved. There had been a wide range of approaches in how to deal with management or better yet how to improve management functions in our ever changing environment. From the Pre- Scientific era to the modern day management, from Frederick Winslow Taylor to Peter Drucker, management has evolved from being mere concept to a matter of experience. It's been a process of transformation from the management theory of jungle to the modern day contingency and empirical school of thoughts. Along with these changes, the outlook, the approach towards working in organizations has changed inevitably.
From the Darwinian's concept of survival of the fittest and cut throat competition, management has grown matured enough to discuss the utmost need for ethics, values, morals and spirituality. The introduction of the Human resource department as a term because of the fact that humans are now considered as resources (and even assets in some cases), signifies the fact that now we are focusing on the behavioral and social aspects of employees and have reached a phase where we need to halt and consolidate to look upon the future in a broader way. This piece of study is an attempt to explore the trends of management and offer some practical tools to create an impact in the ongoing practices in the management corridors. 
The advent of spirituality in the corporate corridors shows its marks only a decade ago. It was towards the end of the $20^{\text {th }}$ century that ethics, morals and values gained some voice. It was then in the beginning of $21^{\text {st }}$ century that the urge to think more seriously and deeply about inculcating ethical and moral behavior in the form of a conduct was recognized. Corporate examples of BCCI (Bank of Credit and Commerce International) of Pakistan, Enron Corporation of Houston, Texas, LDDS WorldCom of United states, Tyco international of Princeton, New Jersey, Kanebo Limited of Japan, Waste management inc. of Houston, Texas, Parmalat of Italy, Health South Corporation of Birmingham, Alabama, USA, American International group (AIG) of Shanghai, China, Satyam Computer of Hyderabad, India, Scandal of Xerox, Bernie Madoff's Ponzi Scheme, the Stanford Financial Fallout, The Galleon Greed Scandal, Duke Energy, Home Store.com, peregrine system, the recent $2 \mathrm{G}$ scam, show that in all the cases trust built first to bubble status, and then only it popped. More than that the large public accounting firms, viz. Arthur Andersen, Deloitte \& Touche, Ernst \&Young, KPMG and Price Water House Coopers either admitted to or faced charges of negligence in the execution of their duty as auditors for failing to identify or prevent the publication of falsified financial reports by their corporate clients (Sullivan, 2006)

Workplace Spirituality or Spirituality in the Workplace is a movement that began in the early 1990s. It emerged as a grassroots movement with individuals seeking to live their faith and/or spiritual values in the workplace. One of the first publications to mention spirituality in the workplace was Business Week, June 5, 2005. The cover article was titled "Companies hit the road less traveled: Can spirituality enlighten the bottom line?" Thompson (2001) denotes that spirituality at workplace has to do with how you feel about your work whether it is a job or a calling. Neal and
Jerry (2003) define it as "Spirituality in the workplace is about people seeing their work as spiritual path, as an opportunity to grow personally and to contribute to society in a meaningful way. It is about learning to be more caring and compassionate with bosses, subordinates and customers. It is about integrity, being true to oneself and telling truth to others. It means attempting to live your values more fully in your work". Sheep (2004) defines spirituality at workplace through four components: selfworkplace integration, meaning in work, transcendence of self and personal growth of one's inner life at work.

But it was all like the case of blind men and the elephant. Whoever was holding the elephant from whichever part, was describing the elephant in his own way, without ever seeing it. The Western school of thought based on modernizing concepts could never ever match the solutions available in the East. Deeper discussions and explorations revealed that the solution lies in the text and scriptures of the country where the term Spirituality was born in India. It was then when the West started looking towards the East and establish new code of conducts based upon a deeper sense of value based humanitarian approach. It was the time to understand what spirituality is and how can it be introduced in the corporate houses.

These individual deepest values and meanings when collectively aligned in a group create a circle of value based initiatives and puts the founding stone of a Spiritual Business Unit (SBU). There needs to be a greater sense in the present day's organizations to enhance the value base of each and every employee. After all the question business leaders need to answer isWhich value needs to be exchanged among them and their team members. What value do I as an employee bring home towards the end of the day? Do I come home frustrated, deprived, anguished or hurt; or do I reach back with a sense of 
achievement, greater hope, meaning and purpose for the next day, some new learning to share with my own people, and after all a smile on my face. Does my organization sends me home with cherishing memories and compassionate instances of the day or some bad patches to crib upon? Do I feel the urge for waking up next day and reaching out to my organization as my second home where I spend more than half of the waking time, or do I get the blues every day? Answers to these simple practical questions leave us with the understanding of a spiritually built and run organization. John Elkington's 3BL although do draw some attention on People and Planet other than Profit motives but very less efforts have been made in this direction for the simple reason being practically these do not go that well hand in hand as the moral bankruptcy of the organization does not support the combination of profit (the traditional bottom line) with the much needed Social and Environmental cause.

We are not human beings on a spiritual journey; we are spiritual beings on a human journey (Chardin, 1955). Spirituality is an element that is within the essence of each employee, and it can't be separated from the employee, whether a business decides to acknowledge the spiritual aspect of humankind or to ignore the spiritual essence, but a business cannot make spirituality vanish from humanity. A deeper understanding of spirituality is therefore necessary to promote employee success, which may lead to selfactualization and employee satisfaction. The concept of spirituality has been discarded since long in the West as the real meaning has always been misapprehended with religious practices and activities. There has always been a perplexing and mystifying undertone on such talks till recent times, but simply understanding, spirituality is the understanding of the meaning and purpose, whether it is to do with personal life of professional organizational life. A SBU increases the sense of satisfaction of the employee and extends to her/ him a delightful event to cherish upon, as she/ he knows that the performance is based upon values like honesty, integrity, trust, respect, togetherness and compassion. A sense of greater purpose drives the employee to perform with full zeal dedication and devotion, beyond the thinking of mere paychecks and this sense of greater purpose is considered to be spiritual. Spirituality guides behavior. It as well impacts the response of an employee towards the change. As there sustains an environment of trust, help, cooperation and not competition in a SBU, the response to change is always positive and the transition is comparatively smoother.

Since a SBU follows a unique set of practices based upon ethics and morals it enjoys a classy culture, very different and very exclusive. This distinctiveness ensures efficacy among the employees and creates a positive executive performance. An environment of learning and a spirit of growing together get established as a value in such SBUs. As we understand, more satisfied are the employees, lesser is the attrition. Employees remain motivated to the level of excellence and perform at a greater level of consciousness. The internal drive for excellence and not success yields team performance, higher dedication, deep sense of commitment, and of course, no doubt about higher profit margins.

Hence we can see that when employees enjoy values and feel more meaning and purpose in the organizations they work for, profits follow with high margins. The Spiritual Quotient of such employees is always the vital contributing factor.

\section{Way to Build a Spiritual Business Unit}

Building a SBU is a two way process of mutual exchange of values and principles among the employees and the employer. It is a connection of one with the whole, one soul with the higher soul; similarly one employee's value system with the organization's value culture. When two Buddha meets they become one, when thousand Buddha 
meets, they also become one. All rivers when meet the ocean loses their identities and become ONE. They lose their sweetness and acquire the salty taste of the Ocean. The natural sense of community in us makes us commune with the rest of the world. This helps us align with the organizational objectives and remain in communion with the same.

One atom in the Universe cannot move without dragging the whole world along with it. There cannot be any progress without the whole world following in the wake. The soul of the Universe and thy soul are same. Similarly the individual and the organization grow together. The growth should be holistic. This is to be considered as one of the basic principles in building a strong SBU.

\section{Variables of spiritual climate for business organization}

Following variables of spirituality in organization have been identified to build a spiritual organization. The variables of meaningful work, hopefulness, and authenticity are related to harmony with self. Sense of community and respect for diversity are related to harmony in work environment and meditative work, and Loksangrah are related to transcendence aspect of workplace spirituality.

Representation of spiritual climate variables:

\begin{tabular}{|c|c|c|}
\hline Dimensions & Sub Constructs & Definition \\
\hline \multirow{4}{*}{ Harmony with self } & Meaningful work & $\begin{array}{l}\text { Work for life not only for livelihood (Ashmos and Duchon, } \\
2000) \text {. }\end{array}$ \\
\hline & Hopefulness & $\begin{array}{l}\text { Individual determination that goals can be achieved and belief } \\
\text { that successful plans can be formulated and pathways can be } \\
\text { identified to attain the goal (Snyder, 2000). }\end{array}$ \\
\hline & Authenticity & $\begin{array}{l}\text { Alignment of people's actions and behaviors with their core, } \\
\text { internalized values and beliefs (Pareek, 2002). }\end{array}$ \\
\hline & Sense of community & $\begin{array}{l}\text { Experience of interconnectedness and interdependence of } \\
\text { employees (Jurkiewicz and Giacalone, 2004). }\end{array}$ \\
\hline \multirow{3}{*}{$\begin{array}{l}\text { Harmony in } \\
\text { environment }\end{array}$} & Respect for diversity & $\begin{array}{l}\text { Adapting a plural way of accommodating the multiplicities } \\
\text { and diversities of societies and individuals and operates on } \\
\text { shared opportunity and shared responsibility (Zohar, 2004). }\end{array}$ \\
\hline & Meditative work & $\begin{array}{l}\text { Experience of being absorbed in work, losing sense of self, } \\
\text { and becoming one with the activity (McCormick, 1994). }\end{array}$ \\
\hline & Loksangrah & $\begin{array}{l}\text { Working for world maintenance (Radhakrishnan, 1951); } \\
\text { Concern for social and natural environment. }\end{array}$ \\
\hline Transcendence & \multicolumn{2}{|c|}{ Concern for social and natural environment } \\
\hline
\end{tabular}

In order to obtain a Spiritual Business Organization, is to require training just like technical training. Spirituality is not an attribute that can be acquired without education. Spirituality is a journey from non-spiritual to spiritual. A SBU implements Spiritualized Leadership, Performance Systems Metrics, and a Spirituality Quotient. It supports both employees who desire a spiritual work environment and employees who might be indifferent to a SBU. Employees experience spirituality as a guiding force or a higher power (Mitroff \& Denton, 1999). The guiding force or the higher power intertwines with work and influences behavior. The connection is to support behavior with performance (Harrington, Preziosi \& Gooden, 2001). In a SBU employees and leaders search for meaning in the business organization. A SBU is 
selfless and reflects shared values. The purpose statement of the organization is reflected in the organization's values. The organization should intertwine spirituality and profits. A SBU is an expression of meaning and a place in which spirituality is expressed (Gull \& Doh, 2004).

Following are some postulates proposed by the patron founder of Thought Revolution movement, reverend Spiritual Guru, Pt. Sriram Sharma Acharya (Acharya, 1956), which imbibes the guidelines for building a strong SBU:

\section{Postulate (1): Abiding with the essential disciplines of the Divine principles}

Everlasting and rich organizational cultures are based on practicing tested disciplines. Any healthy culture is the outcome of divine healthy practices. 'Divine', this might sound a mismatch with respect to corporate. But at the same time we do have examples of benchmarked practices by corporate. This can be easily replaced with the term Humanitarian.

The personality of any corporate house is reflected by its actions, deeds, initiatives, culture, people and of course the key decision makers. Let's take the example of TATA motors, when Ratan Tata says at the launch of Nano, "Promise is a promise, and it has to be kept" (Tata, 2009). Now this is a reflection of strong character based upon divine values.

Another good example is of JRD Tata with Smt. Sudha Murthy (W/O Narayan Murthy), for her recruitment in the Tata Sons as the first ever lady. She quotes that once she was waiting for her husband to come and pick her up. JRD stood by her during the wait time and reflected a leadership quality of strong will and character blended with parental care. Such examples showcase the value based DNA of the organizations, which starts from the top and come down to create a culture and represent the high value system of the organization.
Actionable: Start from the top and bring in values based changes throughout.

Postulate (2): Regarding the body as a temple of God, we will be ever watchful to keep it healthy and full of vitality by adopting the principles of self-restraint, order and harmony in our daily lives.

Health is wealth. Often we ignore our body and stop regarding it as a vehicle for conducting and achieving the best in the world. HR departments emphasize on providing physical infrastructure \& amenities like Gymnasium, pools, recreation corners, etc but at the same time the competition and greed to earn more leaves the employee with no thought for his body and no focus on health. Yog is making its importance felt but that too more like a culture statement and limited to Aasan, Pranayam and not as a Way of being.

Actionable: Create meditation corner/ peace corner; yog as a compulsory practice for atleast $15 \mathrm{mins}$ in the morning and $15 \mathrm{mins}$ in afternoon, to keep employees fit and afresh; Check the menu at Cafeterias, if any- offer sprouts, curd, beans and other vitamin rich food as it keeps both body and mind fit and fresh.

The Huffington shares in its news article titled- "Mindfulness in the corporate world: How businesses are incorporating the Eastern practice", that companies like Google, Target, General Mills, etc are incorporating meditation to make their employees more mindful as a daily practice at workplace.

Postulate (3): With a view of keeping our minds free from the inrush of negative thoughts and emotions, we will adopt a regular program of study of ennobling and inspiring literature and of keeping the company of saints.

Corporate Rishi or Corporate Sufi could be the new buzz in the business houses in the coming days. It is high time to Indianize the Western practices and find a way out for the unwanted 
problems. Good companionship, good literature and elevated people nurture and shape our personalities, which in-turn creates an organizational culture. Spiritual space/ meditation corners/ Yog rooms/ Reading zones, should be accessed more as compared to Smoking zones and posh cafeteria. Some organizations, although do create such opportunities and experiences for its employees through competitions and CSR initiatives.

Actionable: Study corner with inspiring, ethical and moral based literature, case studies \& biographies of value based organizations/ people/ institutions/ civilizations, etc should be given focus. Also, regular training workshops and brainstorming sessions on such topics should be organized.

Postulate (4): We will vigilantly exercise strict control over our senses, thoughts, emotions and in the spending of our time and resources

Imagine what can happen if this principle can be fully adopted and practiced in our business houses. No harassment, no back stabbing, proper time and resource management, safe and harmonious environment, familial bonding between colleagues, and a holistically progressive approach.

Actionable: Sri Aurobindo said, "When you evolve, the whole environment around you evolves." If we can manage our senses, inner resources like thoughts, feelings, passion, gratitude, love, anger, hatred, jealousy, etc, we can as well manage it all around us.

Corporate houses like IBM, Google, Infosys, Tatas, practices strict rule books in their daily routines.

Postulate (5): We will consider ourselves as inseparable parts of the society and will see our good in the good of all.

'Oneness with the whole'. Such was the principle of our ancestors and that's what made us self sustainable, diverse, peaceful and contented. Corporate Social Responsibility (CSR) has got its real essence in this principle of the East. Now a days, most of the Corporate houses just visit some slums and conduct plantation activities to name it CSR. All this is pomp and show with no real societal will at the back.

Actionable: Find the special areas of interest of employees; determine their social orientation and initialize them to create activities of CSR rather than leaving it in the hands of a set of people under the department. What we mean to suggest is that CSR initiatives should be employee (people) driven; the department should help execute it.

Postulate (6): We will abide by the basic moral code, refrain from wrong doing and will discharge our duties as citizens committed to the well being of the society.

A nation's culture is the collective outcome of its citizen's/ and organization's culture. It is the Eastern teaching which shows us the path of integrative approach to holistic development.

Actionable: The following exhibit makes it clearer:

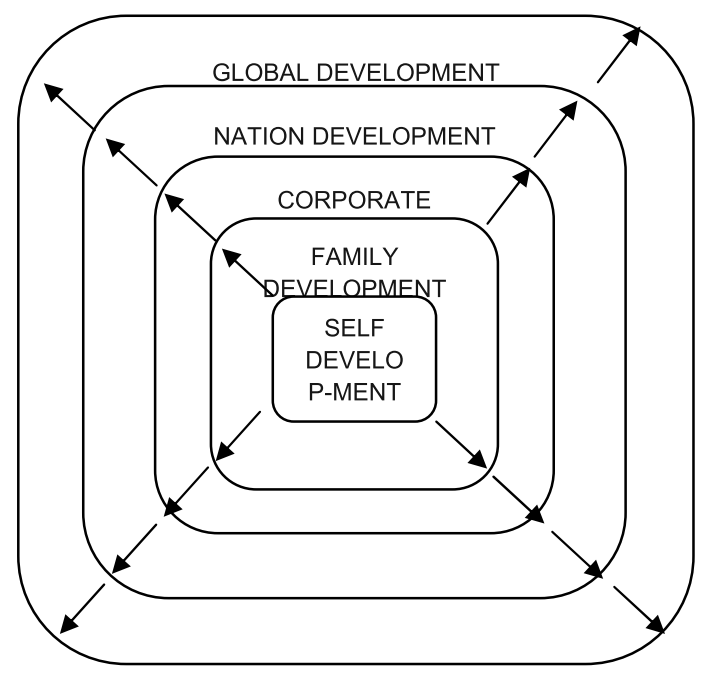

If the policy makers, management and decision makers keep this view in mind and create opportunities to build such a culture they can not 
only fatten their bottom line but also contribute to the CSR. In-fact the CSR should be replaced by ISR (Individual Social Responsibility).

Postulate (7): We will earnestly and firmly imbibe in our lives the virtues of wisdom, honesty, responsibility and courage, and will constantly and sincerely endeavor to create an environment of loving kindness, cleanliness, simplicity and good will.

Wisdom to do the right things, honesty to our own selves, responsibility to commit and contribute and courage to follow a principled employee life; such attributes should gain focus in the Assessment centers of the HR department and strategic policies.

Actionable: Create an honesty counter at the work place, example a stationary counter or a cash drop counter at cafeteria. Let people use the drop box to put in the money they want against the things/ eatables they consume. Observe the collection against inventory at the end of the day. This is a very effective tool to find the level of thinking among employees, honesty, loyalty and trust towards the organization and may reflect to the HR related issues like attrition. The more the loyalty, the better is the trust and faith and lesser will be the attrition. This shall also indicate the moral and ethical patterns of the employees at a large and how much do they refrain from the basic moral code.

Postulate (8): We will prefer failure while adhering to basic moral principles to so called success obtained through unfair and foul means.

We wish Ramalingam Raju- Founder Chairman of Satyam, Kenneth Lay, Founder Chairman and CEO Enron \& Skilling- COO Enron, Bernie Ebbers, CEO WorldCom and many more would have learnt and imbibed this principle in their daily practices. Not only them, until unless all of us as responsible employees of our respective institutions abide to this principle, we will never be able to tackle any of the personal, societal, institutional or national issue in life.

Actionable: An organization is there to exist for long. Abide strongly to the corporate governance practices and ethics to ensure its long term life.

Postulate (9): We will never evaluate a person's greatness by his worldly success, talents and riches, but by his righteous conduct and thoughts.

The ever failing and dissatisfying Appraisal systems of the institutions fails because the evaluation patterns are based on the output, success, targets, client base, etc. Imagine an appraisal system focusing on the righteous conduct and thoughts will encourage an indomitable will among the employees.

Actionable: Create Appraisal system, which rate human value systems, practices of the employees, their conduct at the office, initiatives and motives in different activities, along with the talent, skills and other KRA related parameters.

Postulate (10): We will never do unto others what we would not like to be done unto us.

"Be the change you want to see", Mahatma Gandhi ji. If the top management starts practicing what they preach, organizations will become a heavenly place to work for. Top management should focus on this and cautiously practice everything on them before communicating it down to the rest of the organizational levels so as to make it a culture.

Have a look at these statistics: Only $45 \%$ feel that their managers behave in a way which is consistent with company values. Only 35\% feel that what their organisation says it values is consistent with what it actually rewards. After all, it's not what you say, it's what you do (The National Business Ethics Survey, 2009). 
Actionable: Bring in the trust factor among employees and create an environment of mutual respect, integrity and transparency.

Postulate (11): We will regularly and religiously contribute a portion of our time, talents and resources for spreading nobility and righteousness in this world.

This principle of the Indian culture is the fundamental block of CSR initiatives. This is exactly what we meant by ISR-Individual Social Responsibility. This value shall surely get reflected first at the office work place and among the family as these are the 2 places where an individual spends most of his/ her time.

Actionable: Initiatives like Performance with Purpose of Pepsi Co., which ensures that the growth happens with a Purpose and therefore happens in the interest of all are to be replicated.

Postulate (12): We will actively involve ourselves in bringing together people of goodwill, in resisting evil and injustice, and in promoting New Creation.

Community initiatives by corporate houses should be based on this principle. 3M, Google, Toyota are some good corporate examples who promote creativity and have policies and systems in place to ensure justice. They not only promote innovation, but also are known for low attrition rates and retaining employees for longer terms and generate goodwill among them.

Actionable: Spread the word among other organizations and help them through case studies and field initiatives.

Postulate (13): We will remain committed to the principles of national unity and equality of all human beings. In our conduct we will not make any discrimination between person and person on the basis of caste, creed, color, region, religion, language or sex.
The buzz of Globalization is the prime Vedic concept called 'Vasudhaiv Kutumbakam'. From Darwinism (survival of the fittest) to Gandhism (survival of the weakest/ poorest), there is a huge gap which needs to be filled. The fight of the fittest always encourages the animal instinct and on the name of competition again gives rise to the unethical and unhealthy practices. Here is an exhibit of the same (Sharma, 1996):

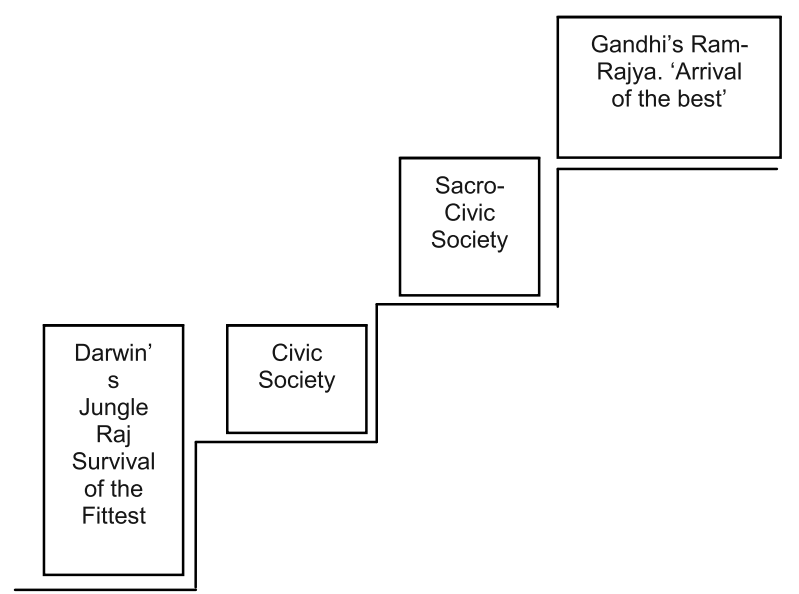

Postulate (14): We firmly believe that each human being is the maker of his own destiny. With this conviction, we will uplift and transform ourselves and help others in doing so. We believe the world will then automatically change for the better.

Luck is a loser's excuse for a winner's position. It is the hardship and conviction which leads result, and not the circumstances. Indian Rishi says that human has got the immense capability of changing circumstances by just drawing a shift in his state of self. This approach can be helpful for the institutions to look forward and rectify the ongoing wrong practices for a better future.

To summarize, the 3 elemental teaching of the Vedic scriptures are U.S.A. This acronym stands for Upasana, Sadhana, \& Aradhana. Upasana means Develop. Develop yourself, your employees, your organization for good. Focus on creating holistic wealth not only profits. Sadhana means 
Control. Once we develop the goodness, then it is important for us to control it. Terrorists, Uncivilized elements of society are examples of people with immense potential with developed abilities but guided in the wrong direction. Gandhi ji rightly said, "Mankind is moving fast, but unfortunately in the wrong direction. Aradhana means Utilize. The last step is to disseminate what one have generated and accumulated. Share what you have developed and grow together as an organization or society or nation.

The governance of the corporate house and institutions, in both crisis and smooth sailing situations should focus on utilizing these learning as building blocks of their culture. Only when these become the fundamental ingredients of the organizational personality, will we not face such Ethical bubbles and reports like NBES will have different findings.

\section{Conclusion and Recommendations}

SBU model offers a sustainable competitive advantage for increased profits, business performance, leadership, employee satisfaction and employee retention. The leader's task is to create an environment that will foster a culture of commune, empathy, faith, trust and belongingness.

Some recommendations are as follows: (a) Economic Value Added should be replaced by Human Value Added. Focus should be paid on how much value has been added to the human resources and how much have they contributed as a result of alignment. (b) Shift in the mindset from the Survival of the Fittest philosophy which leads to cut throat competition to the Arrival of the Best approach, which ensures a win-win situation of learning from the best and developing together. (c) Focusing on Excellence and not Success, as every excellent effort do yield success. (d) Change in approach from Capitalist (individualistic/ money and profit oriented) to Socialistic (developmental/ collective commune). (e) Kaplan's and Norton's Organizational Balance Score Card should give space to Individual Balance Score Card. As the organizational performance is measured on the parameters of Finance, Customers, Processes and Learning \& Growth; similarly, Individual should be rated on the 4 quadrants of SQ, IQ, Communion with peers- customers- and stakeholders, and Productivity \& Efficacy.

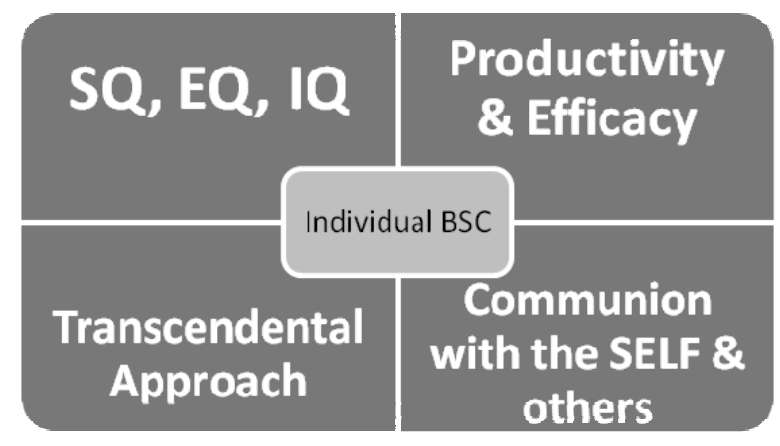

Figure (2): Individual Balance Score Card

Quadrant (1): SQ, EQ \& IQ: Spiritual quotient (SQ) is described as a measure that looks at a person's spiritual intelligence in the same way as intelligence quotient (IQ) looks at cognitive intelligence, while EQ deals with the emotional stability in different situations.

Quadrant (2): Transcendental Approach: This is a unique approach as taught in Indian scriptures, especially Geeta when Arjuna had to fight against his own family members but yet stand by the values, ethics, truth and honesty.

Quadrant (3): The productivity and efficacy of the employee in terms of value contributed to the organization shall also be measured.

Quadrant (4): Communion with the SELF and others: How well does one manage to remain connected with her/ his real self, as the Self is the righteous guide and leads us to righteousness? Also, how does one reflect the same communion with others?

ANKUR MEHTA, MBA, Research Scholar, Dev

Sanskriti Vishwavidyalaya, Haridwar, India 


\section{REFERENCES}

Acharya, P. S. S. (1956). Yug Nirman Sat-sankalp: The Solemn Pledge. Haridwar: AWGP

Ashmos, P. D. \& Duchon, D. (2000). Spirituality at work. Journal of Management Inquiry, 92, 134-145.

Chardin, P. T. D. (1955). The phenomenon of man. Longon: William Collins

Galen, M. ( 1995, June 4). Companies hit the road less traveled. Business week Archives. http://www.businessweek.com/stories/1995-06-04/companieshit-the-road-less-traveled

Gull, G. \& Doh, J. (2004). The transmutation of the organization: Toward a more spiritual workplace. Journal of Management Inquiry, 13(2), 128-139

Harrington, W. J., Preziosi, R. C. \& Gooden, D. G. (2001). Perceptions of workplace spirituality among professionals and executives. Employee Responsibilities and Rights Journal, 133, 155-165.

Elkington, J. (1997). Cannibals with forks: The triple bottom line of 21st century business. Capstone: Oxford University Press.

Jurkiewicz, C. L. \& Giacalone, R. A. (2004). A values framework for measuring the impact of workplace spirituality on organizational performance. Journal of Business Ethics, 492, 129-135.

McCormick, D. W. (1994). Spirituality and management. Journal of Managerial Psychology, 96, 5-9

Mitroff, I. I. \& Denton, E. A. (1999b). A study of spirituality in the workplace. Sloan Management Review, 40(4), 83-92

Neal, J. \& Jerry, B. (2003). Research on spirituality in organizations: Issues, methods and findings. Journal of Organizational Change Management, 16, 26-32.
Pareek, U. (2002). Training Instruments in $H R D$ and $O D\left(2^{\text {nd }}\right.$ Ed). New Delhi: Tata MacGraw Hill Publishing Company.

Radhakrishnan, S. (1951). Indian Philosophy. London: George Allen and Urwin.

Sharma, S. (1996). Management in new age: Western windows Eastern doors. New Delhi: New Age International Publishers.

Sheep, M. L. (2006). Nurturing the whole person: The ethics of workplace spirituality in a society of organizations. Journal of Business Ethics, 664, 357-369

Snyder, G. (2000). The Gary Snyder reader. Washington, DC: Counterpoint.

Sullivan, V. (2006, Februray 16). Corporate Accounting Scandals/ 2006-R-0122. OLR RESEARCH REPORT. Available at http://www.cga.ct.gov/2006/rpt/2006-R-0122.htm

Tata, R. (2009). Speech at the launch of Tata Nano. The Economic Times. http://articles.economictimes.indiatimes.com/ 2009-03-29/news

The Huffington post (2012, August 29). Mindfulness In The Corporate World: How Businesses Are Incorporating The Eastern Practice. www.huffingtonpost.c0m/2012/08/29/ mindfulness-businesses-corporate-employees-meditation

Thompson, W. (2001). Spirituality at work. Executive Excellence, 18(9), 10.

Zohar, D. (1997). Rewiring the corporate brain (p. 120). San Francisco, CA: Berrett-Koehler Publishers

${ }^{1}$ Corporate governance is the set of processes, customs, policies, laws, and institutions affecting the way a corporation (or company) is directed) 